\title{
Cardiac arrest in special circumstances: Toxic alcohol poisoning
}

Gabriela Raluca Grigorasi1, Mihaela Corlade1,2, Ovidiu Popa1,2, Anca Haisan1,2, Paul Nedelea2,

Catalin Bouros2, Cristina Popescu2, Diana Cimpoesu1,2*

1 University of Medicine and Pharmacy "Grigore T. Popa"-Iasi

2Emergency Department, Clinical Emergency County Hospital "St. Spiridon”-Iasi

* Corresponding author. E-mail: dcimpoiesu@yahoo.com

Purpose of the study:

Poisonings with metabolically toxic alcohols occur for many reasons: accidental ingestion (particularly in children), suicide attempt or work accidents.

Toxic alcohol poisoning can be associated with a significant degree of morbidity and mortality if not promptly recognized and treated. This study aims to evaluates toxic alcohol poisoning signs and symptoms, an approach to diagnosis and management and to determine the incidence of cardiac arrest.

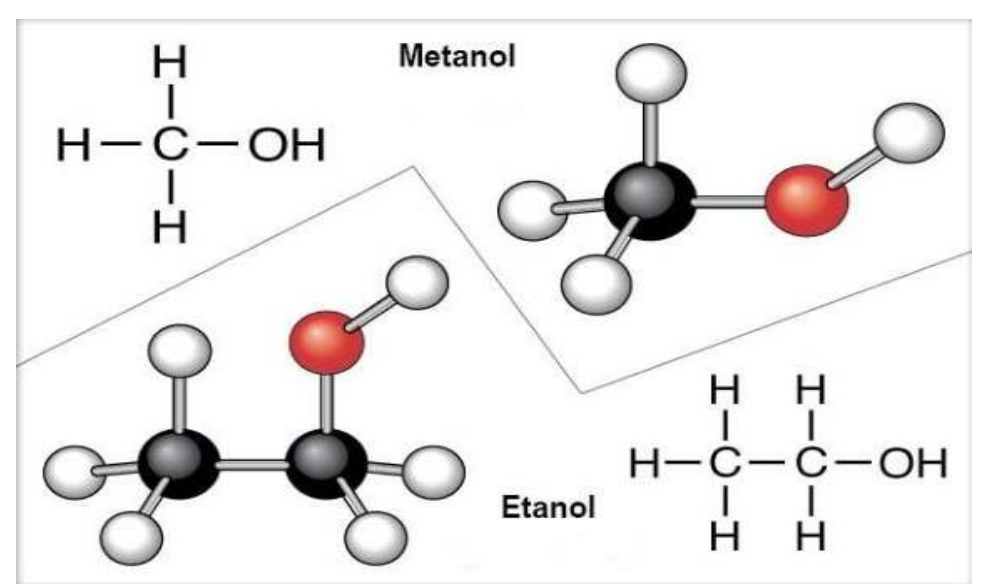

Material and Methods:

Retrospective descriptive study conducted between January 2016December 2018. This study included all patients diagnosed with toxic alcohols intoxications, admitted to the Emergency Department (ED) of 'St. Spiridon ' Hospital Iasi - Romania.
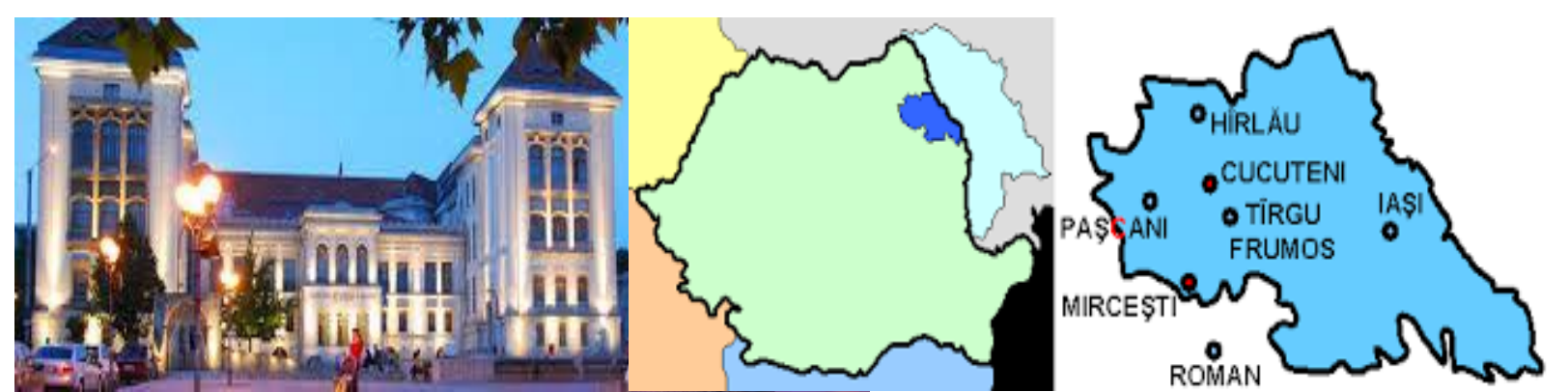

The selection of cases was based on the diagnosis received on admission, patients or witness's statements and the results of laboratory tests that confirmed the ingestion of toxic substance.

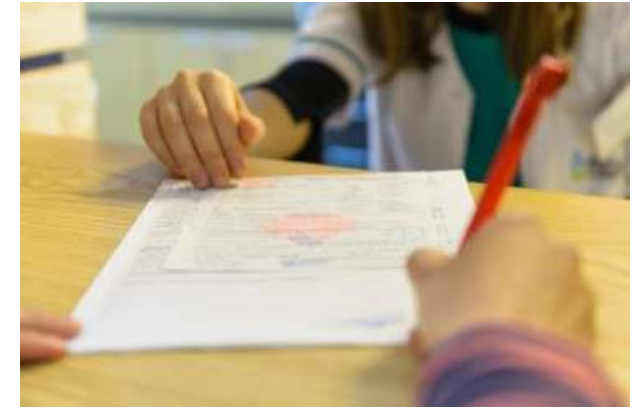

\section{Results:}

Our study included 192 patients (aged between 19 and 90, mean age 44.14 years), poisoned with ethanol $(60.41 \%)$, ethylene glycol $(25 \%)$ and methanol (14.59\%).

$$
\text { Ethanol - voluntary }
$$

Patient distribution based on the ingestion type
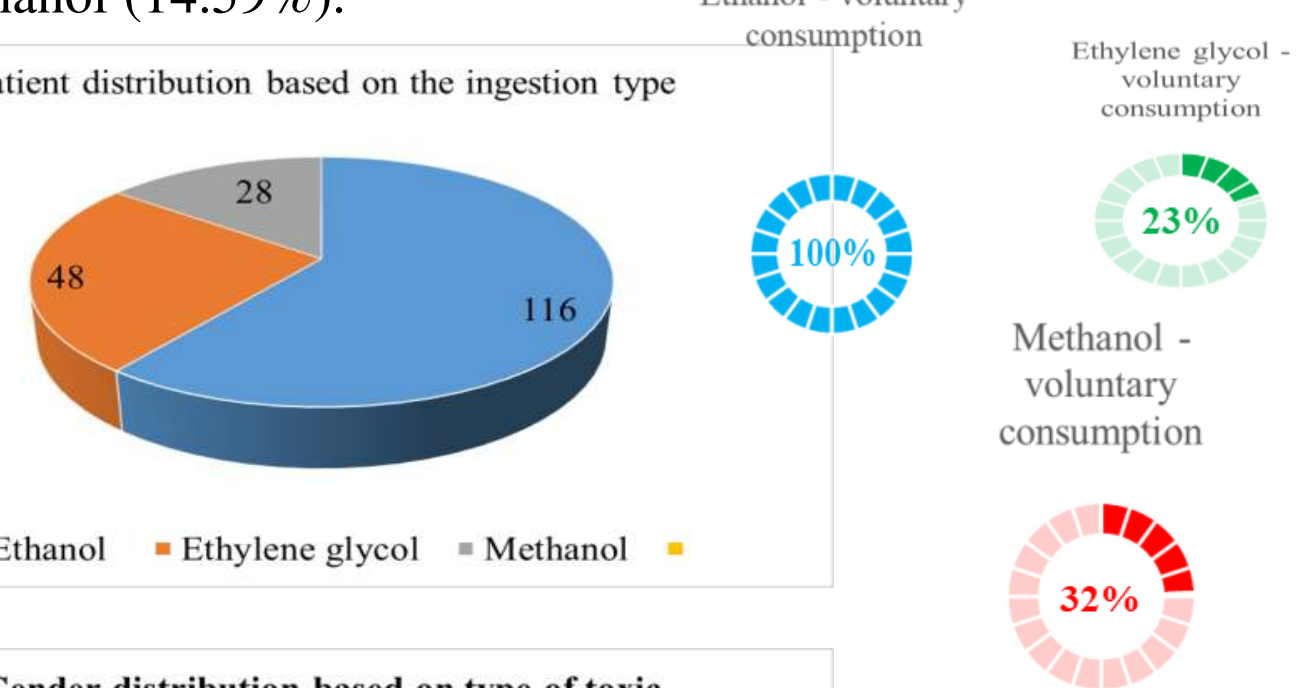

Gender distribution based on type of toxic
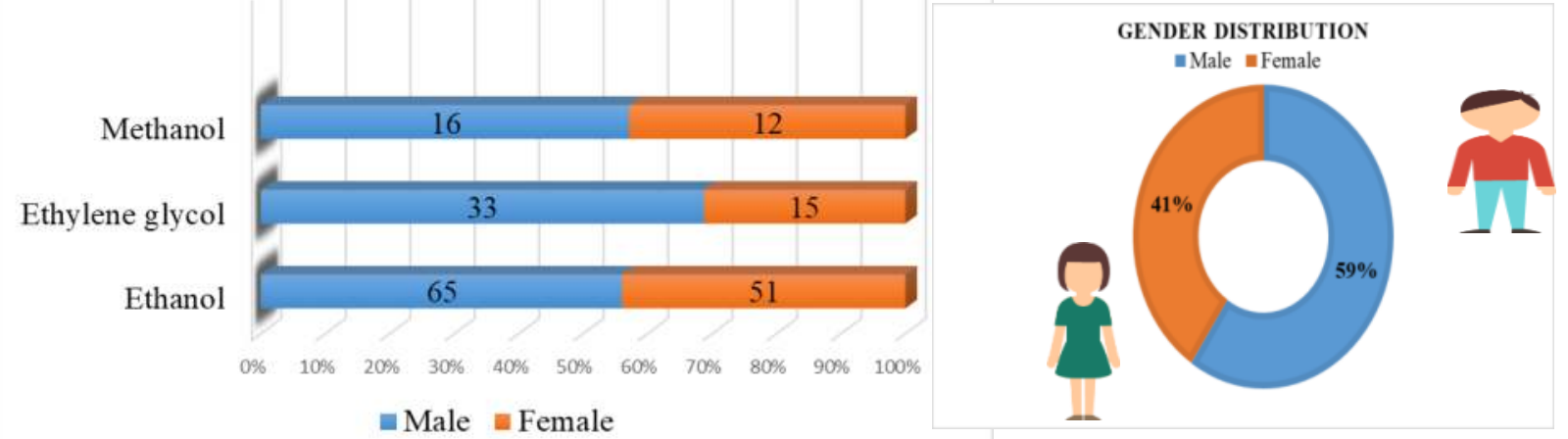

The residents of rural areas showed a slightly increased inclination towards toxic alcohols ingestion (61.97\%).
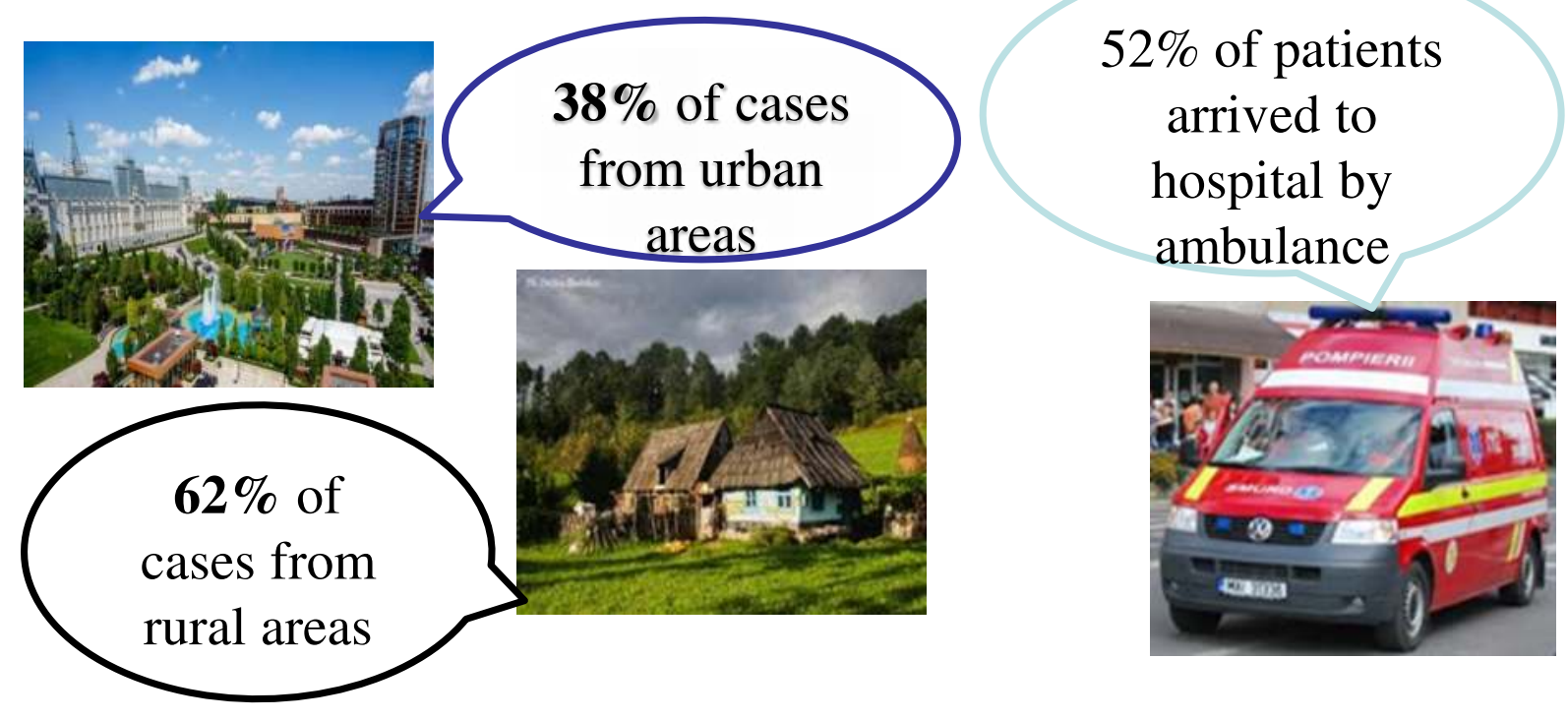

\begin{tabular}{l|llr}
\hline \multicolumn{4}{|c}{ TABEL 1. Cardiorespiratory arrest cases-evolution } \\
TYPE OF TOXIC & ETHANOL & $\begin{array}{l}\text { ETHYLENE } \\
\text { GLYCOL }\end{array}$ & METHANOL \\
\hline $\begin{array}{l}\text { GCS <8 } \\
\text { (PATIENTS, \%) }\end{array}$ & $5,4.31 \%$ & $8,16.66 \%$ & $5,17.85 \%$ \\
$\begin{array}{l}\text { OROTRACHEAL } \\
\text { INTUBATION (\%) }\end{array}$ & $5,4.31 \%$ & $8,16.66 \%$ & $5,17.85 \%$ \\
DEATH (\%) & $1,0.86 \%$ & $6,12.5 \%$ & $3,10.71 \%$
\end{tabular}

This patients (18 cases of cardiorespiratory arrest) had a creatinine greater than 1.0 $\mathrm{mg} / \mathrm{dL}$ and an alkaline reserve less than $22 \mathrm{mmol} / \mathrm{L}$, on arrival. At admission, more patients who subsequently died (10 cases) had seizures $(5.2 \%)$, were comatose $(9.37 \%)$, severely acidotic ( $\mathrm{pH}$ 7.05) and with compromised renal function, than survivors

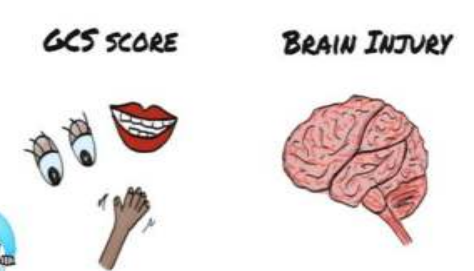
$(94.79 \%)$

Conclusions:

Toxic alcohol poisoning can be an elusive diagnosis.

Patients are critical from the beginning and this lifethreatening situation must be early recognized and establish of an emergency treatment.

The early diagnostic and exclusion of other type of poisoning leads to a specific treatment of intoxication. 